\title{
A POLITECNIA NO BRASIL: HISTÓRIA E TRAJETÓRIA POLÍTICA
}

\begin{abstract}
The goal of this article is to rescue the recent historical period about the Polytechnic in Brazil, through its main authors. Also we will detail the most important characteristics of the Polytechnic, as well as the two stages of its historic and conceptual development. The first one, the 80s, was demarcated by Taylorist and Fordist production and by a new political and democratic process in Brazil. At that moment, the Polytechnic proposal fights to be hegemonic in the educational system. The second one, in the $90 \mathrm{~s}$, the authoritarian neoliberal project toke place and the Polytechnic proposal had new interlocutors and new questions to answer, until a new educational law replaces it. At last but not least, we show some of the internal problems related to the Polytechnic constructed in the last 20 years with the intention to open a discussion.
\end{abstract}

Key Words: Polytechnic School, Shool Legislation, Brazilian Education History.

\section{RESUMO}

Este artigo tem como objetivo resgatar o período historicamente recente da Politecnia no Brasil, através de seus principais formuladores. A partir daí, procura mostrar as principais características da Politecnia, bem como destacar os dois estágios de seu desenvolvimento histórico e conceitual. O primeiro, nos anos 80 , no contexto marcado pela

\footnotetext{
* Professora Doutora (Adjunto) no Departamento de Administração e Planejamento Educacional da Universidade Federal de Alagoas.
} 
produção taylorista-fordista, revigorado pela luta pela redemocratização do país. Nesse momento, a Politecnia luta para se tornar uma proposta hegemônica no contexto do sistema educacional brasileiro. O segundo estágio, nos anos 90 , quando o projeto neoliberal assume o poder, com caráter fortemente autoritário. A proposta passa a ter novos interlocutores e novos questionamentos, até uma nova LDB tomar o seu lugar. $\mathrm{O}$ artigo conclui mostrando alguns problemas internos na formulação da Politecnia nestas duas décadas, com o intuito estimular e fazer avançar o debate teórico-prático.

Palavras-chaves: Escola Politécnica, Legislação Escolar, História da Educação Brasileira.

As discussões em torno da escola politécnica bem como da escola unitária ${ }^{1}$ no Brasil ganham força nos anos 80 , ou seja, num período da nossa história política, econômica e educacional ainda muito recente. Esse período ficou marcado como o momento da abertura política, da transição democrática do regime militar para o regime civil, denominado de Nova República, cujo final culminou nas eleições de 1989. A vitória de Fernando Collor de Mello demarca a instauração de uma nova etapa política e econômica no Brasil. $\mathrm{O}$ neoliberalismo passa a ser a orientação política do país.

Este estudo buscará discutir estas raízes recentes da politecnia e da escola unitária no Brasil, considerando também suas principais características e seus desafios político-pedagógicos.

\subsection{O contexto brasileiro}

O regime militar deixou muitas marcas na educação brasileira, especialmente através das leis 5540/68 e 5692/71, que modificam o sistema de ensino nos três níveis: fundamental, médio e superior. Em

${ }^{\mathrm{I}}$ É importante notar que a escola politécnica e a escola unitária vêm sendo apresentadas no Brasil a partir dos anos 80 , muitas vezes como se fossem idênticas. 
relação ao ensino médio, a Lei $5692 / 71$ teve uma importância particular, porque transformava, obrigatoriamente, todo o então ensino de $2^{\circ}$ grau em escolas profissionalizantes, até à reforma da Lei 7044/ 82 , que acabou com essa obrigatoriedade. A partir de então, o ensino profissionalizante passou a ser oferecido majoritariamente em escolas especialmente voltadas para o aprendizado de uma profissão específica.

No contexto produtivo, predominava a base tecnológica e organizacional taylorista-fordista, e, a partir dos anos 80 , já começa a ocorrer um processo de conversão tecnológica em alguns setores de empresas multinacionais instaladas no país, adotando tecnologias japonesas. E importante acrescentar que, nos países mais desenvolvidos, o taylorismo-fordismo foi marcado por um forte investimento na área social por parte dos Estados, o que garantiu uma certa estabilidade social e, principalmente, garantiu amplamente a educação básica das crianças e dos jovens. No Brasil, não observamos o mesmo fenômeno.

Segundo Ferreira, o taylorismo foi um tipo de organização de trabalho que

se adaptou a uma matriz tecnológica já constituida a partir da divisão da mecanização, não obstante seja verdade que a aplicação da 'gerência científica' tenha propiciado certa renovação do instrumental de trabalho então utilizado e melhor adequação desses instrumentos ao processo de trabalho 'taylorizado' (há uma seleção, uniformização e aperfeiçoamento dos meios de trabalho. (Ferreira, 1984: 754)

O taylorismo pode ser definido como um processo de trabalho baseado no pleno domínio sobre os tempos da produção e dos movimentos dos operários, através da base tecnológica, com forte redução do grau de autonomia dos trabalhadores ligados diretamente ao processo produtivo.

Já o fordismo, segundo Ferreira, representa tanto uma extensão quanto uma superação do taylorismo: 
Suas inovações em relação ao taylorismo podem ser resumidas - grosso modo - em dois aspectos principais: a introdução de uma linha de montagem (e aí serão consideradas as mudanças ao nivel do processo de trabalho) e o aparecimento de alguns elementos de uma nova politica de gestão da FT2 (notadamente, uma nova política de salários). (Ferreira, 1984: 755)

A linha de montagem representou a mecanização da circulação dos objetos e dos meios de trabalho no processo produtivo, adquirindo maior integração dos segmentos e redução do deslocamento dos trabalhadores. $O$ resultado foi uma maior fixação dos trabalhadores nos postos de trabalho, significando um aperfeiçoamento do controle dos tempos e movimentos, reduzindo a porosidade da jornada de trabalho. Ferreira acrescenta que tais mudanças "acentuam o caráter fragmentado, repetitivo e monótono do trabalho, já herdado do taylorismo". Era ainda uma produção baseada na padronização tanto das peças quanto do produto final. Essas mudanças representaram um elevado aumento do rendimento do trabalho e uma queda no valor unitário da peça produzida.

As mudanças na política salarial tinham a finalidade de elevar o padrão salarial dos trabalhadores como forma de enfraquecer as resistências dos operários à linha de montagem, prejudiciais à produção. Muitos dos critérios para a elevação dos salários estavam condiconados ao comportamento dos trabalhadores, que deveriam seguir normas disciplinares rigorosas, dentro e fora das fábricas. Essa política salarial também tinha por finalidade uma mudança nos padrões de consumo dos trabalhadores, representando, segundo Ferreira:

Uma primeira tentativa no sentido do estabelecimento de novas normas de consumo operário, compatíveis com as novas normas de produção engendradas pela difusão do taylorimo e do fordismo no seio dos aparelhos produtivos. Porém essa tentativa encontrou sérios obstáculos que se explicam, em grande parte pelos estreitos

${ }^{2}$ Força de trabalho. 
limites colocados pelos imperativos de rentabilização imediata do capital privado. (1984: 757)

Essa tensão só poderia ser resolvida no âmbito do Estado, na medida em que estende sua política em benefício da força de trabalho, como a previdência social, particularmente após a crise de 1930. E acrescenta:

Essa mesma questão pode ser vista também sob a ótica das condições de acumulação do capital; desse prisma, a formação de um novo padrão de consumo operário aparece como uma necessidade para compatibilizar as condições de realização do capital (ou, em outros termos, a demanda efetiva) com as novas condições de produção de massa de mais-valia (advindas das transformaçōes verificadas no processo de trabalho). Essa compatibilização entre produção e realização do capital viabilizará os regimes de acumulação sobre uma base intensiva, havendo consolidação e prosperidade dos mesmos principalmente no pós-guerra e nos países centrais do sistema capialista. (Ferreira, 1984: 757)

De fato, uma das conquistas mais importantes para os trabalhadores naquele período de consolidação da base tayloristafordista de produção foi o Estado de Bem-Estar Social. O tipo de trabalhador demandado pelo processo produtivo taylorista-fordista era o operário desqualificado, ou seja, um trabalhador com muita resistência física e psicológica, pouca criatividade e muita submissão, que conseguisse tolerar um ritmo de trabalho muitas vezes estressante. A escolaridade exigida era mínima. A gerência, por sua vez, era composta por profissionais com alto nível de escolaridade e com alto domínio técnico-burocrático, capaz de criar e desenvolver novas tecnologias voltadas para a produção, sendo considerados, portanto, altamente qualificados.

Nesse sentido, é possível afirmar que o taylorismo e em particular o fordismo, representaram uma mudança substancial não só nos padrões de produção como no modo de vida dos indivíduos. Como bem destaca Clark: 
Com a generalização dos métodos de produção fordistas, outros fabricantes logo entraram no mercado de massa, oferecendo aos consumidores da classe média um leque de opções que até então só estava disponivel para os ultra-ricos. (Clark, 1991: 134)

O taylorismo-fordismo também apresentou algumas conseqüências importantes para a organização dos trabalhadores. Consolidou o processo de subsunção real do trabalho ao capital, como Marx havia apontado, e, ao mesmo tempo, por necessitar de um grande contingente de trabalhadores diretamente inserido no processo produtivo e em conglomerados industriais, propiciou a união dos operários e favoreceu os movimentos sindicais. Nos países mais desenvolvidos, essa tendência fortaleceu-se com as políticas do Welfare State, as quais promoveram inúmeras conquistas sociais. No Brasil, essas conquistas ficaram restritas a alguns segmentos mais organizados e fortes dos trabalhadores. Não chegaram, portanto, a consubstanciarem-se em uma política geral de bem-estar social, apesar de representar alguns avanços.

Segundo Mattoso (1995), o Brasil entra tardiamente nessa Segunda Revolução Industrial em relação aos países desenvolvidos, em consequiência de uma política de substituição de importações adotada por Getúlio Vargas. E a partir do pós-guerra o país implanta uma economia urbana e industrial própria da produção industrial taylorista-fordista.

Com o Plano de Metas e a industrialização substitutiva foram implantadas as indústrias pesadas, de bens duráveis etc. tendo por base um vigoroso tripé formado pelas impresas transnacionais, estatais e privadas nacionais que completará a industrialização com autodeterminação do capital através do seu núcleo central: a indústria pesada. (Mattoso, 1995: 123)

A economia brasileira se diversifica e se torna complexa, gerando transformações na estrutura social e no mercado de trabalho, fortalecendo a classe operária e os segmentos da classe média. Ao mesmo tempo, surgem as desigualdades regionais e o aumento da pobreza, em decorrência dos baixos salários. 
Durante a década de 80 cresce o fortalecimento dos trabalhadores e dos sindicatos no país, ao mesmo tempo em que começam a aparecer alguns sinais de crise nesse modo de produção. Ainda assim, permanece o padrão dominante, com a introdução ainda insignificante de produção baseada nas técnicas japonesas, já largamente implantadas nos países mais desenvolvidos desde a década de 70. Segundo Mattoso, esse dado é importante para a compreensão da "dinâmica aparentemente contraditória da economia, do mercado de trabalho e dos sindicatos no período" (137). No nosso entender, traduz também a ênfase da discussão sobre a educação politécnica e sua crítica ao tipo de educação profissionalizante voltada para atender às características do trabalho desqualificado da produção tayloristafordista.

Ainda nos anos 80, nosso PIB foi o de maior crescimento da América Latina e apresentou o maior superávit comercial através do incremento das exportações. O mercado de trabalho variou de acordo com as flutuações da atividade produtiva e não pela introdução de novas tecnologias, ao mesmo tempo em que o trabalhador sofre uma progressiva perda de seu poder de compra em decorrência dos baixos salários, acentuando a desigualdade social. Esse quadro sócioeconômico, favoreceu seu fortalecimento político, como mostra Mattoso.

Quanto à organização dos trabalhadores, a consolidação do movimento de ampliação democrática iniciado na década anterior em meio a uma relativa preservada da estrutura produtiva permitiu que (...) o movimento sindical brasileiro assumisse nova dimensão, reconquistando direitos, organizando centrais sindicais, lutando contra a estrutura e a legalidade repressiva oficial, elevando os níveis de sindicalização, fortalecendo suas organizações de base, ampliando o espaço para negociações coletivas e conquistando amplo reconhecimento social. (Mattoso, 1995: 138)

Esse fortalecimento político dos trabalhadores nos anos 80 repercutiu numa forte pressão pela democratização do país e na luta 
pela ampliação dos direitos sociais mínimos. Mas, mesmo considerando alguns avanços alcançados por certos setores e regiões brasileiras, o quadro social se agrava com a precária implantação do Welfare State no país, comprometendo o crescimento da melhoria da qualidade de vida da população e da qualidade da educação pública.

Segundo Aureliano e Draibe (1989), há várias categorias de welfare state, mas, basicamente, pode ser caracterizado pelo forte investimento do Estado nas seguintes áreas sociais: saúde, educação, alimentação e habitação, asseguradas como um direito e não como assistência. Esses itens tendem a ser alterados de país para país, podendo inclusive incorporar a previdência social e programas de renda mínima e salário-desemprego, entre outros. As autoras apontam algumas características do Welfare State brasileiro a partir de 1964, destacando:

1. extrema centralização política e financeira no nível federal das ações sociais do Governo;

2. excessiva fragmentação institucional, com excessiva burocracia, ausência de mecanismos públicos de controle e superposição de programas e clientelas;

3.exclusão da participação social e política da população nos processos de decisão, demonstrando seu caráter autoritário;

4.o princípio da privatização, que significa que o usuário deve pagar pelo que recebe, abrindo espaço para interesses privados dentro do próprio Estado, ao mesmo tempo que diminui sua participação. Os principais recursos seriam provenientes das fontes fiscais prejudicados pelo alto índice de sonegação de impostos - as contribuiçōes sociais e o fundo patrimonial - que recaem sobre o salário dos trabalhadores, principalmente os assalariados de baixa renda - e, por fim, as contribuições das empresas. Esse sistema se mostrou sem efeito distributivo.

As autoras definem o sistema brasileiro como meritocráticoparticularista, o que significa que:

Cada um deve estar em condições de resolver suas próprias necessidades, em base a seu trabalho, a seu mérito, à performance profissional, à produtividade. A política social intervém apenas parcialmente, corrigindo a ação do mercado. $O$ sistema de 
welfare, por importante que seja, é tão somente complementar às instituiçōes econômicas. (Aureliano e Draibe, 1989: 114)

Esse projeto político relega um papel secundário à ação social do governo, voltando-se apenas aos que não conseguem atender suas necessidades através do mercado, configurando-se, portanto, um projeto "conservador" de progresso social, assentado em um quadro de miséria absoluta por uma grande parcela da população, fenômeno que não ocorreu nos países desenvolvidos. Este é o saldo do regime militar para a Nova República, que assume comprometendo-se a solucionar essa "dívida social", agravada pelos elevados índices de desemprego.

A Nova República busca cumprir o prometido através de Planos de Emergência, cujos alvos são a fome, o desemprego e a miséria. Fruto do processo democrático, a sociedade reivindica que as propostas de política social deveriam conter critérios socialmente mais justos. Assim, foram incorporados ao discurso oficial alguns temas, tais como: a descentralização, traduzida como municipalização e privatização, com a participação popular nas decisões, na implantação e no controle das políticas. Nesse período surgiram também as práticas de desinstitucionalização, pela distribuição de cupons e vales, em convênio direto com a iniciativa privada.

Segundo Aureliano e Draibe, a Nova República confere um peso relevante aos problemas sociais, com um estatuto de política social, como um direito à cidadania, principalmente após a instalação da Assembléia Nacional Constituinte, que iniciou seus trabalhos em 1987, contribuindo para o avanço das conquistas sociais.

A Assembléia Nacional Constituinte marcou um período importante para a discussão e socialização da temática educacional e, especificamente para o debate em torno da Politecnia. Foi uma tentativa de renovar a sociedade, eliminando os vestígios do autoritarismo militar e estender e consolidar direitos sociais, com a participação de amplos setores organizados da sociedade.

Com o processo de abertura política, iniciado pelos militares no final dos anos 70, e com o fortalecimento do movimento dos trabalhadores, havia todo um clima político e intelectual favorável à 
retomada das discussões por autores socialistas sobre a temática do papel social e político da educação em geral e da educação dos trabalhadores em particular, delineado por esse contexto. O movimento dos trabalhadores também crescia em importância política no cenário nacional, culminando com a criação do Partido dos Trabalhadores, em 1980.

No início dessa década, favorecida por tal quadro social e político, as propostas de educação "politécnica" e de "escola unitária" começam a ser delineadas e apresentadas teoricamente. Conforme aponta o estudo de Rodrigues (1993), o conceito de politecnia não é novo no Brasil. Atribui sua atual sistematização e divulgação a Dermeval Saviani e seus orientandos, principalmente Gaudêncio Frigotto, Lucília Machado e Acácia Küenzer. A origem da proposta da Politecnia encontra-se em Owen, um socialista utópico, que mais tarde Marx e Engels vão apontar como um dos bons exemplos de educação para os trabalhadores da Inglaterra na segunda metade do Século XIX.

A politecnia tem sido estudada através de Marx, e a escola unitária, através de Gramsci, ambas consolidadas pelos autores que mais influenciaram a teoria da educação, dos anos 80 até hoje. Segundo Rodrigues, aí estaria "o embrião fundamental do trabalho como princípio educativo, que busca na estruturação da sociedade seus aportes básicos" (1992:32). O autor afirma ainda que o mais importante não é a concepção de politecnia apresentada por Marx, mas as diversas "interpretações" e as suas "conseqüências" para o debate nacional.

\subsection{A contribuição de Dermeval Saviani}

Dermeval Saviani é um autor muito discutido no país não somente por suas análises em torno da Politecnia. De fato, o autor foi o principal formulador de outra linha pedagógica no Brasil conhecida como "A Pedagogia Crítico-Social dos Conteúdos" ou "Pedagogia Histórico-Crítica", que não será o objeto deste estudo.

Suas contribuições tornaram mais claro o papel político e social da educação no nosso cenário educacional. Destacou, nesse sentido, 
o papel político da educação e dos conhecimentos aí transmitidos. Por esse caminho, começa a levantar pontos importantes da relação entre trabalho e educação e a resgatar as propostas de Gramsci e Marx, como formas alternativas à formação dos trabalhadores.

Dermeval Saviani marcaria as discussões na elaboração da Politecnia de forma decisiva. Em um texto publicado em 1989, o autor discute a sua proposta de politecnia mais detalhadamente. Nesse momento é possível perceber alguns eixos temáticos que, de maneira geral, estarão presentes nas obras de seus orientandos e que são centrais na definição do conceito no Brasil. Cabe notar que toda a discussão em torno da Politecnia, para Saviani, se concentra no ensino de $2^{\circ}$ grau, como uma proposta altenativa à Lei 5692/71, que generalizava a profissionalização do ensino. Os principais eixos são estes:

1. A politecnia deriva da problemática do trabalho, entendido como seu princípio educativo geral. Assim define o seu conceito de trabalho e de homem:

Se é o trabalho que constitui a realidade humana, e se a formação do homem está centrada no trabalho, isto é, no processo pelo qual o homem produz a sua existência, é também o trabalho que define a existência histórica dos homens. Através do trabalho o homem vai produzindo as condições de sua existência, e vai transformando a natureza e criando, portanto, a cultura, criando o mundo humano. (...) Conforme se modifica o modo de produção da existência humana, portanto o modo como ele trabalha, produz-se a modificação das formas pelas quais os homens existem. Nesse sentido, é possivel detectar ao longo da história diferentes modos de produção da existência humana, que passa pelo modo comunitário, (...) e o modo de produção capitalista. (Saviani, 1989: 8-9)

2. A importância de a escola resgatar o conhecimento, expropriado pelo processo produtivo capitalista, particularmente sob o processo produtivo taylorista-fordista.

O "Taylorismo" desempenhou um papel importante, já que a partir do estudo do tempo e movimento, foi possivel detectar 
quais eram as tarefas simples que cada trabalhador tinha que desenvolver a fim de contribuir para a produção de determinados produtos. Uma vez isso sistematizado, é desenvolvido na forma parcelada, e o conhecimeno relativo ao conjunto passa a ser propriedade privada dos donos dos meios de produção, ou seus representantes, aqueles trabalhadores intelectuais que representam os donos dos processos produtivos. (Saviani, 1989: 14)

3. Crítica da divisão entre trabalho manual e intelectual na formação escolar, fruto da divisão entre trabalho manual e intelectual no processo produtivo, no ensino de $2^{\circ}$ grau.

Trata-se de organizar sim, oficinas, quer dizer, processo de trabalho real, porque a politecnia supõe a articulação entre o trabalho manual e o intelectual. Isto será organizado de modo a que se possibilite a assimilação não apenas teórica, mas também prática, dos principios científicos que o aluno já conheceu a partir do primeiro grau, (...) agora ele terá que compreendê-los não apenas no seu caráter teórico, mas também no seu funcionamento prático, numa compreensão teórica e prática desses princípios. (Saviani, 1989:18)

4. Os conhecimentos científicos e tecnológicos, base do processo produtivo moderno, seriam também a base da escola fundamental e secundária. $\mathrm{Na}$ escola elementar, através das ciências da natureza e da sociedade; no segundo grau, na combinação destas com o processo produtivo.

A sociedade moderna, desenvolvida a partir do advento do capitalismo, é uma sociedade que revoluciona constantemente as técnicas de produção, que incorpora os conhecimentos como força produtivas. É a sociedade que converte a Ciência, que é potência espiritual, em potência material através da indústria. (Saviani, 1989:9) 
5. A definição de uma identidade para o ensino de segundo grau, que elimine a dualidade estrutural da sociedade capitalista que o divide em dois ramos: o propedêutico, voltado para a elite dirigente, e o profissionalizante, voltado para a classe trabalhadora. Nas suas palavras: "A noção de politecnia se encaminha na direção da superação da dicotomia entre trabalho manual e intelectual, entre instrução profissional e instrução geral" (Saviani, 1989:13)

6. A politecnia, definida como uma multiplicidade de técnicas, contrapõe-se à profissionalização estreita da Lei 5692/71, no que se refere ao ensino de $2^{\circ}$ grau, que, apesar de romper (provisoriamente) com a dualidade estrutural, é baseado numa concepção "monotécnica" do trabalho e no ensino profissionalizante.

Politecnia, literalmente, significaria múltiplas técnicas, multiplicidade de técnicas, e daí o risco de se entender esse conceito de politecnia como a totalidade das diferentes técnicas fragmentadas, autonomamente consideradas. A proposta de profissionalização do ensino de segundo grau da Lei 5692, de uma certa forma tendia a realizar um inventário das diferentes modalidades de trabalho, das diferentes habilidades, como a Lei chama, ou das diferentes especialidades. A escola de segundo grau teria a tarefa de formar aqueles profissionais nas diferentes especialidades requeridas pelo mercado de trabalho. (Saviani, 1989:16)

E complementa:

Ora, a noção de politecnia não tem nada a ver com este tipo de visão. A noção de politecnia diz respeito ao domínio dos fundamentos cientificos das diferentes técnicas que caracterizam o processo de trabalho produtivo moderno. Diz respeito ao fundamentos das diferentes modalidades de trabalho. Politecnia, nesse sentido, se baseia em determinados princípios, determinados fundamentos e a formação politécnica deve garantir o domínio destes principios, desses fundamentos. (Saviani, 1989:17) 
O autor não define suficientemente o que seriam essas diferentes modalidades de trabalho, mas acrescenta, que são elas o seu princípio, o elemento fundamental da politecnia. $O$ argumento principal contra a educação profissionalizante, como está na Lei em questão, seria o seu caráter de adestramento, ou seja, " a profissionalização é entendida como um adestramento em uma determinada habilidade sem o conhecimento dos fundamentos dessa habilidade e, menos ainda, da articulação dessa habilidade com o conjunto do processo produtivo" (1988: 09). Também aqui, a afirmação é um pouco vaga, não traz indicadores dessa falta de fundamentos e de articulação.

Outra crítica a essa concepção de profissionalização contida nessa Lei diz respeito a um tipo de formação de trabalhadores, meramente para a executação de algumas tarefas: "forma-se trabalhadores para executar com eficiência determinadas tarefas requeridas pelo mercado de trabalho" (1989:14). No seu entender, o modelo proposto pela Lei 5692 sobre o ensino profissionalizante forma o trabalhador para executar tarefas de acordo com o mercado de trabalho, o que não seria o ideal para a formação dos trabalhadores.

7. Estabelecimento de um vínculo mais direto do então $2^{\circ}$ grau, com o trabalho.

No segundo grau a relação entre educação e trabalho, entre conhecimento e a atividade prática deverá ser tratada de maneira explicita e direta. O saber tem uma autonomia relativa em relação ao processo de trabalho do qual se origina. O papel fundamental da escola de segundo grau será, então, o de recuperar essa relação entre o conhecimento e a prática do trabalho. (Saviani, 1988:09)

Como exemplo de como a atividade prática do trabalho pode contribuir para demonstrar a relação entre trabalho e ciência nas oficinas escolares, cita a transformação da madeira e do metal pelo trabalho humano, pois "envolve não apenas a produção da maioria dos objetos que compõe o processo produtivo, mas também a produção de instrumentos com os quais esses objetos são construídos". (1988: 09) 
É possivel acrescentar mais três temáticas que complementam a proposta:

8. A politecnia deve ser um projeto a ser realizado no âmbito da escola pública de qualidade, universal e gratuita, não somente para o ensino básico, mas também para a educação secundária, como afirma: "implica a progressiva generalização do ensino de segundo grau como formação necessária para todos, independentemente do tipo de ocupação que cada um venha a exercer na sociedade". (Saviani, 1988:09)

9. A politecnia deve visar à formação multilateral dos homens.

Não se trata de um trabalhador que é adestrado para executar com perfeição determinada tarefa, e que se encaixe no mercado de trabalho para desenvolver aquele tipo de habilidade. Ele terá um desenvolvimento multilateral, um desenvolvimento que abarca todos os ângulos da prática produtiva moderna na medida em que ele domina aqueles princípios, aqueles fundamentos, que estão na base da organização da produção moderna. Dado que a produção moderna se baseia na Ciência, há que dominar os princípios científicos sobre os quais se funda a organização do trabalho moderno. (1989:17)

10. A politecnia não deve ter vínculo direto com o mercado de trabalho, pois a formação voltada para o mercado de trabalho é a antítese da formação politécnica, pois teria um caráter limitado e adestrador do homem.

É possível perceber em Saviani que todos esses pontos apresentados estão articulados a partir da noção de trabalho entendido ao mesmo tempo como elemento construtor dos homens e da cultura e do trabalho produtivo. Para Saviani, a discussão da politecnia centrase no nível do $2^{\circ}$ grau por entender que o ensino fundamental já tem o seu currículo organizado na perspectiva cultural científica e tecnológica unitária.

A politecnia, centrada no "trabalho como princípio educativo", parece propor um tipo de educação que supere alguns pontos negativos 
do trabalho taylorista-fordista dentro da escola, como formar trabalhadores mais qualificados, apesar de o mercado exigir trabalhadores desqualificados. Essa proposta sugere também a possibilidade de eliminar, na estrutura do sistema escolar, a divisão social de classes, a dualidade fundamental entre formação geral e formação profissionalizante. Ao mesmo tempo, a escola deve incorporar os aspectos positivos, como o avanço tecnológico.

Portanto, a politecnia para o ensino médio deveria buscar a "unidade indissolúvel" entre trabalho manual e intelectual, entendida como a unidade entre conhecimento teórico e prático, ou seja, nas palavras do autor, todo "trabalho humano envolve a concomitância do exercício dos membros, das mãos, e do exercício mental, intelectual. Isso está na própria origem do entendimento da realidade humana, enquanto constituída pelo trabalho". Deve ainda ser uma proposta que ofereça uma visão globalizante e múltipla dos princípios científicos e técnicos do processo produtivo, que una as dimensões teóricas e práticas. Em síntese, o trabalho deve estar presente na escola pela ciência e pela tecnologia.

Assim, o trabalho permanece o princípio educativo da educação e da escola unitária, que conjuga a formação intelectual e a orientação para o trabalho, ele mesmo, cada vez mais intelectualizado. Ressalta ainda que o desenvolvimento industrial evidencia cada vez mais o caráter ultrapassado da educação brasileira, cuja resistência em modernizar a educação se encontra no próprio goveno federal.

A partir do final dos anos 80 , os orientandos de Saviani começam a ter maior projeção nacional, e suas concepções a respeito de politecnia começam a ser mais difundidas, mesmo que a marca do orientador não desapareça completamente.

\subsection{Politecnia: a difícil busca da hegemonia}

No debate gerado pela Assembléia Nacional Constituinte, as leis formuladas no regime militar foram alvo de intensos e sistemáticos questionamentos, servindo posteriormente, de subsídios para uma proposta alternativa bem como para uma série de críticas à Lei de 
Diretrizes e Bases da Educação Nacional em formulação. Como vimos, esse contexto favoreceu sobremaneira a introdução da temática da escola "politécnica-unitária".

Os conceitos de politecnia e de trabalho como princípio educativo passaram a ser avaliados dentro de suas "possibilidades e limites". O grupo que assumiu e formulou a proposta estava decidido a transformá-la em lei nacional. Foi um momento importante pois, das dúvidas, foram surgindo as tentativas de dar-lhe um perfil mais nítido. As palavras de Maria Laura Barbosa Franco representam o espírito da época.

Apesar das marchas e contramarchas dessa Assembléia e, apesar dos mecanismos conciliatórios de que se valeu para responder aos interesses de diferentes segmentos sociais - o que nem sempre veio ao encontro das expectativas dos educadores comprometidos com os interesses dos grupos sociais majoritários - consideramos importante continuar na luta e aproveitar as brechas de participação que estão se abrindo para a comunidade acadêmica e para as entidades representativas de professores e alunos. (Franco, 1989:30)

A preocupação girava em torno dos avanços que poderiam ser feitos em relação à Lei 5692/71. Assim, como nos mostra Rodrigues, na primeira versão do anteprojeto da LDB, de 1988, do Deputado Octávio Elísio (PSDB/MG), a politecnia aparece, no artigo 35, com uma definição mais próxima à concepção de Saviani: "formação politécnica necessária à compreensão teórica e prática dos fundamentos científicos das múltiplas técnicas utilizadas no processo produtivo" (apud Rodrigues, 1993: 35).

No texto aprovado na Comissão de Educação, Cultura e Desporto, de junho de 1990, do relator Deputado Federal (PSDB/ BA) Jorge Hage, aparece no Capítulo $X$, que tratava do Ensino Médio, no Art. 53, a seguinte redação:

Assegurada aos alunos a integridade da educação básica, que associa à educação mais geral, nesta etapa, as bases de uma 
educação tecnológica e politécnica, conforme disposto no artigo 51, o ensino médio poderá, mediante ampliação da sua duração e carga horária global, incluir objetivos adicionais de educação profissional. (1990:11)

O referido artigo 51 trata dos objetivos específicos do ensino médio, da seguinte forma:

I - o aprofundamento e a consolidação dos conhecimentos adquiridos no ensino fundamental;

$I I$ - a preparação básica do educando para continuar aprendendo, de modo a ser capaz de se adaptar com flexibilidade, a novas condições de ocupação e aperfeiçoamento posterior;

III - o desenvolvimento da capacidade de pensamento autônomo e criativo;

IV - a compreensão dos fundamentos científico-tecnológicos dos processos produtivos, relacionando a teoria com a prática, no ensino de cada disciplina científica. (1990:11)

A versão de Jorge Hage, mesmo não trazendo tão explicitamente a concepção de educação politécnica desejada, mantém o termo no projeto de lei, trazendo alguns pontos complementares ao artigo 51. O conceito de politecnia não entrou no Capítulo XI que trata sobre a Formação Técnico-Profissional, permanecendo no de formação geral. A partir daí, o debate se aqueceu significativamente. Em uma coletânea de publicações sobre a politecnia, organizada pela Secretaria Nacional de Educação Básica, os Cadernos SENEB n ${ }^{\circ}$, de 1991, os próprios deputados colocam algumas dúvidas e críticas a respeito da concepção.

Há um certo preconceito com relação à questão da politecnia. Freqüentemente se associam à questão da politecnia, de um lado, as experiências educacionais anteriores, como a questão do ginásio orientado para o trabalho e do PREMEN. A rejeição da proposta da politecnia está associada a estas duas experiências. De outro lado, há uma resistência à questão da politecnia por 
parte das escolas técnicas. Ai se organiza um lobby extremamente forte, em que as escolas técnicas se acham efetivamente eliminadas do quadro educacional brasileiro pelo fato de o Projeto de Lei de Diretrizes e Bases assumir o compromisso com o ensino de $2^{\circ}$ Grau politécnico. (Elísio, 1991:30)

Outra crítica apontada pelo Deputado considera a proposta extremamente centrada na técnica, desconsiderando seu caráter político-ideológico. Menciona, ainda, entre outros problemas, o conflito motivado pelo consórcio da formação geral e da formação profissional. A identidade da politecnia, que pregava a junção do ensino profissionalizante e propedêutico, acabava tendendo para a formação geral.

O Deputado Jorge Hage, por sua vez, pondera:."seguramente o mais complexo, o menos amadurecido, ou o que requer um debate talvez mais profundo de todos quantos sejam os temas polêmicos sobre os quais nós temos nos debruçado na Comissão e nos debates extracomissão" (Hage, 1991:44). Ressalta a importância de manter a sintonia entre a escola e a realidade e as possibilidades de transformar a realidade a partir da escola.

Outros comentários importantes foram feitos pelo Professor da UNICAMP, José Luis Sanfelice. Eis suas indagações:

Por que a politecnia terá que ser um nível de ensino e não um sistema nacional de educação? Na busca de sua autodefinição politécnica, o ensino médio não se descaracterizaria no âmbito do sistema nacional de educação? E, por outro lado, ao se definir como politécnico, o ensino médio não estaria pretendendo caracterizar este sistema nacional de educação? (Sanfelice, 1991:68/69)

Considera a possibilidade de o conceito de politecnia não estar plenamente entendido e de restringir essa concepção ao $2^{\circ}$ grau, pondo-se em risco a visão de conjunto do Sistema Nacional de Educação. 
Sem dúvida, muitas dessas questões apresentaram-se pertinentes e geraram respostas de seus principais formuladores, que ainda estavam no processo de assimilação e reelaboração dessas críticas, sendo interpelados por uma nova discussão, a polêmica entre politecnia e polivalência, decorrente do debate em torno da crescente implantação da organização japonesa do trabalho na produção.

Nos últimos anos da década de 80 , precipita-se um período de estagnação da economia, desencadeando a suspensão do pagamento da dívida externa, a moratória. Esse novo momento de crise promove o início das políticas neoliberais no Brasil e o debate em torno das transformações da base técnica e organizacional da produção através da introdução das experiências japonesas, já espalhadas pelos países desenvolvidos e outros países da América Latina, tais como o México e o Chile. Esse período demarca o fim da Nova República, que alimentou o sonho de democracia, de justiça social do povo brasileiro, mas na verdade representou apenas um interregno, necessário antes das novas investidas extremamente conservadoras e autoritárias.

As eleiçōes diretas levaram Fernado Collor, o candidato das elites, ao poder. Com ele entramos na era da "Globalização", da produção flexível, da desregulamentação da economia e das leis trabalhistas e sociais da década de 80 . A Carta de 1988, que mal havia sido aprovada, já estava "ultrapassada", segundo os novos dirigentes políticos e econômicos. Com a nova fase política, são fechados todos os canais de intelocução social: a Constituição de 1988 é ignorada e com ela é dada por encerrada a participação social e, com ela ainda, a discussão em torno da "politecnia-escola unitária", numa esfera mais ampla que a do meio educacional.

Com Fernando Henrique Cardoso, sucessor de Collor, ingressamos, finalmente na "modernidade". Crescem em importância outras referências, tais como a competitividade no mercado internacional e nacional, as privatizações, o enfraquecimento dos sindicatos e os movimentos trabalhistas e o desemprego. Essas novas mudanças trouxeram novos elementos contextuais para a discussão da relação entre trabalho e educação no Brasil, que até então permanecia basicamente discutindo o conceito de trabalho desqualificado do taylorismo-fordismo e de um Estado acenando para 
a valorização da área social. No quadro internacional, onde os principais países desenvolvidos, Inglaterra e Estados Unidos, desde 1979 já adotavam políticas neoliberais, outros países eram "influenciados" a adotar as mesmas propostas.

A "politecnia-escola unitária" consolidou-se inicialmente centrando suas críticas no perfil de trabalhador requerido pelas características da produção taylorista-fordista, tradicionalmente conhecida por exigir um treinamento restrito a tarefas repetitivas e limitadas a operações específicas, pois tal forma de organização do trabalho em geral não exige do trabalhador mais que esforço físico no desempenho de atividades, fatigantes e monótonas. Também criticava os cursos técnicos profissionalizantes por oferecerem uma "profissionalização estreita" e monotécnica, voltada para a produção taylorista-fordista.

Os diferentes postos de trabalho presentes na hierarquia da empresa tendem à enfatizar as funções especializadas, numa estrutura social e técnica rígida. É um processo produtivo extremamente desqualificador e embrutecedor. Portanto, nada havia de novo até à eleição de Collor, que cedeu às pressōes internacionais e abriu as fronteiras nacionais para o mercado globalizado, em condições absolutamente desiguais, como não poderia deixar de ser, dada a posição periférica do país nas relações internacionais.

A discussão a respeito do trabalhador polivalente veio acompanhada pelas discussões em torno da produção flexível, esta última identificada com a organização e as técnicas do trabalho japonês. A nova forma de produção representaria a superação das características rígidas, limitadas e desqualificadas da força de trabalho taylorista-fordista e a possibilidade de transformar postos de trabalho desqualificados em mais qualificados, colocando, pelo discurso do capital, a escola novamente em evidência.

A polivalência é discutida na educação pela primeira vez por Vanilda Paiva (1989), quando a autora fez uma avaliação de alguns dos principais autores internacionais a respeito da qualificação profissional e do processo produtivo. A polivalência retorna no contexto das mudanças tecnológicas introduzidas no processo de trabalho industrial com a organização japonesa de produção. A autora discute a questão da seguinte forma: 
Com o desenvolvimento da maquinaria também o trabalhador necessitaria de maior competência técnica, ou seja, a mecanização exigiria a elevação de sua qualificação média. A automação provocaria a diminuição do número de trabalhadores $\mathrm{e}$ promoveria sua reclassificação qualitativa ao criar novos postos de trabalho e novas tarefas. Aumentando as tarefas de manutenção e vigilância estariamos diante da exigência de polivalência do trabalhador. As transformações em curso provocavam o deslocamento de pessoal, especialmente entre aquele ligado à criação, estudo e preparação cujas tarefas se apóiam em conhecimentos científicos e técnicos. (Paiva, 1989: 7)

Isso oferece fortes indicadores de que o desenvolvimento tecnológico não elimina completamente o saber operário, mas o elitiza, pois o número de trabalhadores no chão-de-fábrica diminui, além de aumentar o grau de escolaridade e de qualificação. A autora mostra que nos países desenvolvidos, como a Alemanha, chegou-se a afirmar que a educação profissionalizante não seria menos necessária do que já foi, uma vez que, seriam priorizados outros requisitos profissionais, tais como "flexibilidade, disciplina, autonomia, qualificações sociais" (1989:21), entre outras. Ou seja, habilidades não necessariamente voltadas para o desempenho e conhecimento específicos de uma única profissão ou ramo da atividade produtiva.

Pode-se afirmar, portanto, que um novo perfil de trabalhador e de processo produtivo vem sendo implantado, com características diferentes das introduzidas pelo taylorismo-fordismo. A escola média dual, fundada na divisão entre ensino geral e profissional, estaria prestes à caducar, tendo que adapatar-se às necessidades do novo mercado de trabalho, centrada, agora, em uma ampla formação básica e geral, eliminando a necessidade de ensino profissionalizante e, portanto, eliminado a dualidade estrutural.

A autora ressalta o crescimento do setor terciário da produção e a diminuição do secundário. E acrescenta ainda a seguinte observação: "politicamente pode ser irônico: em curto espaço de tempo vemos bandeiras do movimento dos trabalhadores, como a escola 
única e a qualificação geral, passarem às mãos das empresas em particular e do capital em geral" (1989:51).

Nadya Araújo Castro (1992), posteriormente, pontua as principais características dessa nova abordagem de organização da produção, onde o trabalhador desqualificado cederia lugar àquele capacitado para o desempenho de várias tarefas, sendo, portanto, mais qualificado do que o trabalhador da produção taylorista-fordista:

1. o número de trabalhadores manuais diminuiria em relação aos não-manuais, tais como a consultoria, engenharia de produção, programação, projeto, desenho e marketing na indústria;

2. a organização hierárquica seria superada pela necessidade de maior fluxo de informações entre gerentes e trabalhadores, dado o estreitamento dos vínculos entre planejamento e execução;

3. o controle de qualidade seria integrado ao processo produtivo através do próprio trabalhador buscando a qualidade total;

4. a ênfase recairia sobre o trabalho em equipes, ressaltando a eficiência e a confiabilidade grupal;

5. haveria uma tendência a um crescimento da subcontratação de trabalhadores, muito mais como estratégia de controle social, desarticulação da resistência e estímulo à competição entre os operários, oferecendo em troca, algumas benesses aos trabalhadores estáveis.

A discussão tende a encaminhar-se a fim de propor uma formação de caráter geral, pois é a que mais se adequaria ao novo tipo de trabalho, mais polivalente e flexível, para os trabalhadores, portanto a mais adequada ao novo padrão produtivo que se anuncia. Esse novo perfil geral seria necessariamente o melhor no atual estágio do capitalismo avançado, aumentando as possibilidades de concorrer com sucesso no mercado internacional. Para os trabalhadores representaria a elevação geral do seu patamar de escolaridade.

$O$ resultado foi um certo esvaziamento, sob as relações de produção capitalista, das críticas ao trabalho que ajudaram a construir a proposta de "politecnia-escola unitária" e uma aproximação, no senso comum, de alguns de seus pontos com a noção de qualificação 
defendida pelo capital, no seu estágio "globalizado", causando um certo desconforto. Essa discussão foi tomando mais corpo, envolvendo outros profissionais que não apenas os ligados à educação, tais como sociólogos, economistas e administradores. Essa nova discussão parecia nublar a proposta da politecnia e do trabalho como princípio educativo, ou a escola unitária, enquanto uma possibilidade radical de crítica e uma alternativa nova voltada para os trabalhadores e identificada com a esquerda, tal como se autoproclamava.

Outro fato, dessa vez de nivel internacional, fragilizou as esquerdas no mundo todo. Trata-se do fim dos regimes socialistas do Leste Europeu e da União Soviética. A repercussão deste episódio gerou uma crise entre os defensores do socialismo, provocando algumas desistências, tanto entre intelectuais dos mais diversos países, quanto entre os brasileiros.

A proposta de educação politécnica, voltada para a formação dos trabalhadores, tem toda a sua fundamentação teórica considerando também a sociedade socialista. Sua base teórica e suas análises são socialistas-comunistas. Sua categoria fundamental, o trabalho, tem sido duramente atacada, apontada de ser incapaz de responder aos novos acontecimentos sociais, econômicos e culturais do novo momento histórico.

Seus mais importantes defensores brasileiros, Frigotto, Machado e Kuenzer, buscaram responder a esses pontos levantados. Um dos argumentos em que se mostram unânimes é o que apresenta a Politecnia como uma proposta que não está dirigida para o mercado de trabalho, mas para a formação do homem integral. a politecnia:

Assim, sintetizando um pensamento comum, para Machado

Pressupõe a plena expansão do individuo humano e se insere dentro de um projeto de desenvolvimento social de ampliação dos processos de socialização, não se restringindo ao imediatismo do processo de trabalho. Ela guarda relação com as potencialidades libertadoras do desenvolvimento das forças produtivas assim como com a negação da negação destas potencialidades pelo capitalismo. Se ela está no horizonte histórico, 
o próprio capital enquanto uma contradição em processo é que dirá, bem como a capacidade de luta dos trabalhadores pela sua emancipação. (Machado, 1992:21-22)

O lado positivo dessas críticas foi a tentativa de esclarecê-las. De fato, houve respostas sistemáticas aos questionamentos levantados. Muitas delas presentes em artigos independentes e outras em trabalhos de pós-graduação. O mais significativo, no último caso, é a dissertação de mestrado de Rodrigues, que faz um esforço concentrado de responder a grande parte delas, através dos trabalhos de Machado, Frigotto $^{3}$, Kuenzer, Saviani e Arroyo, especialmente. Seu mérito está em propor a "politecnia" como uma concepção ainda em construção no Brasil, e uma das maiores dificuldades encontradas atualmente é a diversidade de proposições que a temática vem gerando, fragmentando e dispersando o seu entendimento.

$\mathrm{O}$ atual caráter heterogêneo da proposta foi gerado pelas dúvidas que os primeiros autores nacionais provocaram, assim como pela maior visibilidade que o tema alcançou, aumentando o seu interesse. De fato, muitos textos que contribuíram significativamente para avançar a compreensão sobre a politecnia, nem sempre se propuseram a discutíla em particular. ${ }^{4}$

Rodrigues afirma que a proposta de Saviani, ao situar a politecnia no nível de $2^{\circ}$ grau, haveria imputar a esse nivel a "tarefa de explicitar como o saber acumulado pela humanidade converte-se em força produtiva através do processo de trabalho" (1992: 121), além de promover a ruptura com a lógica dual da estrutura do sistema de ensino, como vimos, dividida entre educação para os trabalhadores e educação para a elite dirigente. A escola politécnica deverá ser única, e complementa:

O autor não pretende que a escola supere contradições estruturais da sociedade burguesa, pretende sim que a politecnia aponte a

\footnotetext{
${ }^{3}$ Seu orientador.

${ }^{4}$ Como, por exemplo, Maria Alice Nogueira, Vanilda Paiva, entre outros.
} 
direção dessa superação a partir da realidade do trabalho. Isto é, Saviani propõe que a escola não endosse essa separação posta na sociedade, que não tenha como objetivo formar um educando para o trabalho manual e outro para o trabalho mental. (Rodrigues, 1992: 122)

E acrescenta que a intenção de Saviani não é "adestrar o trabalhador para a execução de uma tarefa específica", mas formar "multilateralmente" o ser humano: "envolvendo todos os ângulos da prática produtiva moderna", representada pela ciência moderna. Percebe-se então por que a proposta de politecnia defendida por Saviani no projeto de lei, tende para o ensino de formação geral e para uma concepção genérica de tecnologia, ainda que não elimine a formação profissional.

Nesse sentido, tanto no que se refere ao princípio geral, quanto à assimilação das bases científicas e tecnológicas aplicadas ao processo produtivo, há uma certa unanimidade entre Saviani, Kuenzer, Machado e Frigotto. Em sua forma de operacionalizá-la, não descartam incluir a formação profissional, sugerindo que deve haver uma completa reformulação nesse ramo do ensino. Em comum, todos têm ainda o fato de que a politecnia deve oferecer uma profissionalização distinta da especialização estreita voltada para um ramo, identificada ao modelo taylorista-fordista de produção, que inspirou a proposta de ensino técnico da Lei 5692.

Rodrigues aponta que não há empecilhos quanto à extensão da politecnia ao demais níveis de ensino, desde o primário ao superior. "Dadas as enormes tarefas que a educação politécnica se põe é lúcido questionar se seus objetivos não extrapolam e muito um determinado nível de ensino ou mesmo o próprio sistema escolar" (1992: 134), o que considera uma postura mais orgânica.

\subsection{Considerações finais}

Cabe ressaltar, que a "politecnia" não é um conceito completamente homogêneo entre seus principais formuladores no 
Brasil, apesar de existirem indicadores de uma tentativa de aproximação de alguns pontos, principalmente no final da década de 80 e início dos anos 90, quando o debate se acirra e se amplia. Os autores, por outro lado, tendem a aproximar significativamente suas concepçōes sobre a politecnia nos principais aspectos levantados até aqui.

Uma característica importante do debate em torno da politecnia promovido por estes autores é o fato de ignorarem ou desconsiderarem completamente as escolas e institutos politécnicos existentes no país, tais como a da USP, a da Bahia etc. De fato, escolas politécnicas já existem no Brasil há alguns anos e é difícil entender por que foram excluídas das análises. Este problema está presente também no que se refere a todas escolas técnicas e profissionalizantes, uma vez que são tratadas genericamente a partir da lei 5692, ignorando suas especificidades, como é o caso das Escolas Técnicas Federais, que se destacam positivamente no cenário nacional.

Outro problema que pode ser considerado é o fato de que esta proposta de Politecnia no Brasil pretende formar para o trabalho, mas sem avançar nas pesquisas envolvendo o mercado de trabalho e a sua relação com a educação.

Estes aspectos reforçam o caráter abstrato da proposta, que além de ter carências de dados empíricos, tem problemas conceituais que não ajudam a uma compreensão adequada da questão, especialmente a associação estabelecida entre escola unitária e politecnia cuja conseqüência mais importante é a impossibilidade de definir coerentemente uma proposta curricular que traduza as intençôes dos autores. Talvez a falta de rigor conceitual seja o problema central da proposta e a origem da polissemia criada em torno do tema. Para os intelectuais que a formularam, com esperanças de vê-la implantada na política educacional, talvez fique a reflexão de que a realidade tem seus próprios caminhos e nem sempre é suficiente que alguns intelectuais formulem idéias interessantes, para que ela seja imediatamente aceita. Aparentemente, tudo estaria resolvido, se assim o fosse.

É importante anunciar o surgimento de uma nova abordagem sobre a discussão da politecnia surgida no Brasil nos primeiros anos 
da década de 90. No Programa de Pós-Graduação da Universidade Federal do Rio de Janeiro, formou-se uma nova linha de pesquisa, que busca oferecer uma nova abordagem teórica dos mesmos problemas, partindo da teoria da Escola de Frankfurt, de Habermas entre outros autores, sob a coordenação do Professor W. Market (1996).

A politecnia perdeu um pouco de expressão nacional com a nova LDB 9394/96, que além de ignorar completamente toda a mobilização e o debate anterior em torno do tema, representa um recuo em termos de ensino profissionalizante no Brasil. Apesar disso, há ainda muito a ser esclarecido, tanto com o auxílio de pesquisas teóricas quanto com pesquisas de campo, para que a politecnia e a escola unitária não se transformem em mais uma moda passageira no meio educacional. Certamente, no caso da politecnia, não foi apenas o novo programa neoliberal que fez com que ela não fosse amplamente adotada. Sua falta de clareza contribuiu para que caísse num certo ostracismo. Se vale a pena trazê-la de volta, depende do fôlego de novas pesquisas.

\section{Referências bibliográficas}

AURELIANO, L. \& DRAIBE, S. M. A especificidade do "welfare State" Brasileiro. In. A política social em tempo de crise: articulação institucional e descentralização. MPAS/CEPAL, Brasília, 1989.

CADERNOS SENEB, Secretaria Nacional de Educação Básica: Brasília, n. 05, 1991.

CASTRO, N. A. Organização do trabalho, qualificação e controle na indústria moderna. In: MACHADO, L. [et.al.] Trabalho e educação. Campinas: Papirus/Cedes; São Paulo: Ande/Anped, 1992.

Reestruturação produtiva e relações industriais. $R B C S, \mathbf{n} .31$, junho/96.

CLARK, S. Crise do fordismo ou crise da social-democracia? Lua Nova, $n^{0} 24$, setembro/91. 
FARIAS, I. M. Diferenças entre polivalência e politecnia. Educação $\mathcal{E}$ Filosofia. 12 (23) 11-29, jan./jun. 1998.

FERREIRA, Cândido G. Processo de trabalho, tecnologia e controle da mão-de-obra. Estudos Econômicos, n 14, set/dez, 1984.

FRANCO, M. L. P. B. Possibilidades e limites do trabalho enquanto princípio educativo. Cadernos de Pesquisa. São Paulo, nº 68, fev. 1989.

. Ensino médio: desafios e reflexões. Campinas: Papirus, 1994.

FRIGOTTO, G. A Produtividade da escola improdutiva. São Paulo: Cortez: Autores Associados, 1986.

- Trabalho-educação e tecnologia: treinamento polivalente ou formação politecnica? Educação e Realidade, Porto Alegre, v. 14, $n^{\circ} 1$, janeiro/junho de 1989.

KUENZER, A. Z. Pedagogia da fábrica. São Paulo: Cortez/Autores Associados, 1989.

. Ensino de $2^{\circ}$ grau. São Paulo: Cortez, 1988.

. O Trabalho como princípio educativo. Cadernos de Pesquisa, São Paulo, n ${ }^{\circ}$ 68, fev. 1989.

- Ensino médio e profissional: as politicas do Estado neoliberal. São Paulo: Cortez, 1997.

MACHADO, L. Educação e divisão social do trabalho. São Paulo: Cortez/ Autores Associados, 1983.

. Politecnia, escola unitária e trabalho. São Paulo: Cortez/Autores Associados, 1991a.

. Politecnia no ensino de segundo grau. In: GARCIA, Walter. (Org.). Politecnia no ensino médio. São Paulo: Cortez; Brasília: SENEB, 1991 b. 
Mudanças tecnológicas e a educação da classe trabalhadora. In: Trabalho e educação. Campinas: Papirus/Cedes; São Paulo: Ande/ Anped, 1992.

MARKERT, W. (org). Trabalho, qualificação e politecnia. Campinas: Papirus, 1996.

MATTOSO, J. A desordem do trabalho. São Paulo: Scritta, 1995.

MATTOSO, J. E. L. Emprego e concorrência desregulada. Campinas: Cadernos do CESIT n. 18, s/d.

NOSELLA, P. O. Trabalho como princípio educativo em Gramsci. Educação e Realidade, Porto Alegre, n 14, jul/dez, 1989.

A escola de Gramsci. Porto Alegre: Artes Médicas, 1992.

. A modernização da produção e da escola no Brasil - o estigma da relação escravocrata. In: Cadernos ANPEd. Porto Alegre, $\mathrm{n}^{\circ} 5$, set. 1993.

PAIVA, V. Produção e qualificação para o trabalho: uma revisão da bibliografia internacional. Rio Janeiro: UFRJ/ Instituto de Economia Industrial, 1989.

PIZZI, L. C. V. "Politecnia" e omnilateralidade no Brasil: um olhar crítico. São Paulo: FE/PUC, 1999. Tese de doutorado.

. Trabalho, educação e qualificação profissional. Maceió: EDUFAL, 1999.

PORCHMANN, Márcio. Politicas do trabalho e de garantia de renda no capitalismo em mudança. São Paulo: Ltr, 1995.

RODRIGUES, J.S. A educação politecnica no Brasil: concepção em construção (1984-1992). Rio de Janeiro: UFF, 1992. Dissertação de mestrado. 
SAVIANI, D. Mudanças organizacionais, Novas Tecnologias e Educação. In: ?.

FERRETTI, C.J. [et.al.] Tecnologias, trabalho e educação. Petrópolis: Vozes, 1994.

Sobre a concepção de politecnia. Rio Janeiro: Fundação Oswaldo Cruz, 1989.

. Contribuição à elaboração da Nova LDB: um início de conversa. ANDE, São Paulo, $\mathrm{n}^{\circ}$ 07, 1988. 